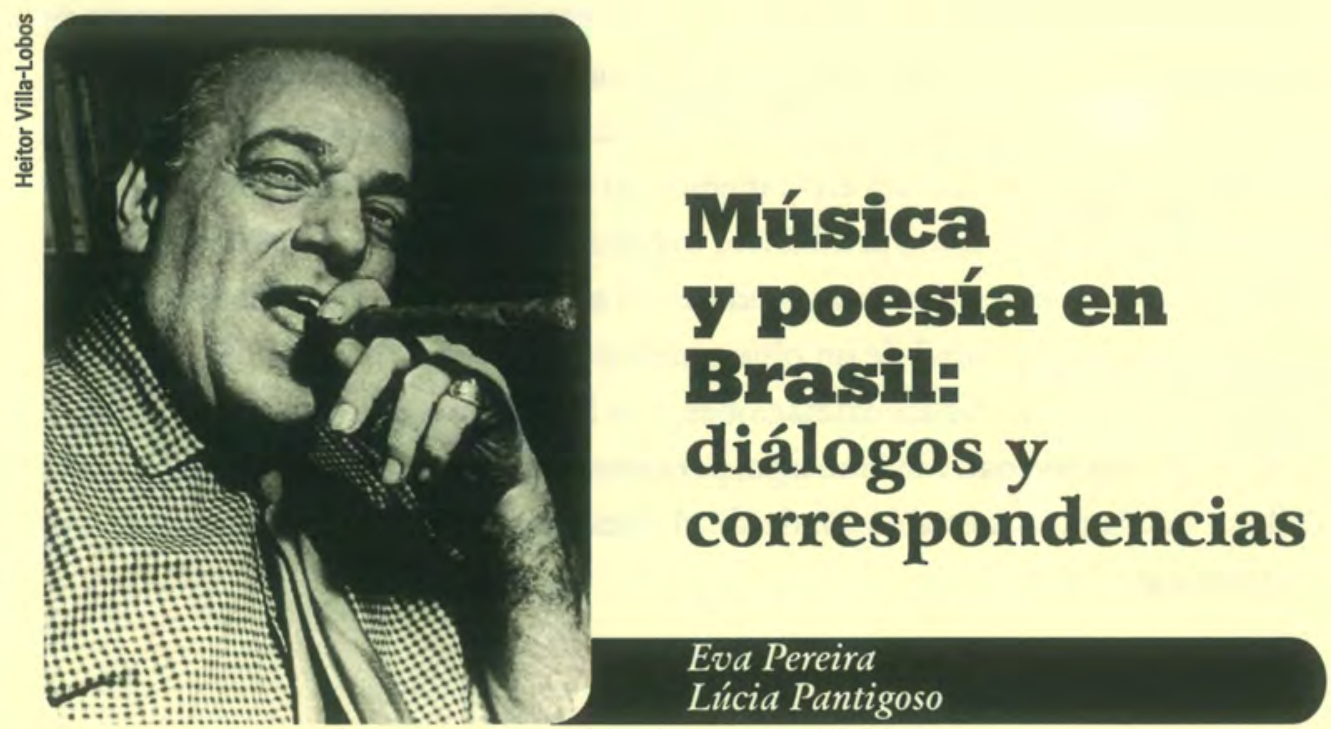

Minha música vem da música da poesia de um poeta João que não gosta de música. Minba poesia vem da poesia da música de um João Músico que não gosta de poesia.

Caetano Veloso, «Outro retrato»

Vou voltar Sei que ainda vou voltar Para o men lugar Foi lá

É ainda lá Que eu bei de ouvir Cantar Uma sabiá Vou voltar Sei que ainda vou voltar

Chico Buarque y Antônio Carlos Jobim, «Sabiá»

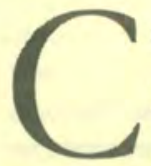

omo afirmó Etienne Soriau, en su clásica obra La correspondencia de las artes, ${ }^{1}$ poesía y música son artes próximas, sobre todo porque las dos son expresiones temporales: dependen de la marcación del ritmo en intervalos de tiempo, de alguna forma previsibles, para su ejecución. De ahí las repeticiones tanto en uno

\footnotetext{
${ }^{1}$ Soruau, Etienne. La correspondencia de las artes. México: Fondo de Cultura Económica, 1986.
} 
como en otro arte, fácilmente perceptible en el caso de la poesía por la presencia de las rimas, los metros regulares, la acentuación métrica, los estribillos, las anáforas, los paralelismos, las aliteraciones y asonancias, etc. Por otro lado, la poesía también se puede aproximar a la pintura en la medida en que tanto una como otra son artes miméticas. Asimismo, como prueban los trabajos de los poetas concretos brasileños a partir de 1950, la literatura también puede ser un arte espacial, ya que produce imágenes o impresiones de realidad de un objeto descrito o representado. En el caso de la poesía brasileña, las dos aproximaciones, con la música o con la pintura, siempre pueden ser observadas. Sin embargo, para este trabajo, nos vamos a detener en el diálogo que la poesía estableció, desde el principio de la cultura brasileña, con el arte musical.

\section{LIRA Y ANTHIRA}

C omo se puede observar en los fragmentos de las letras de las canciones de Caetano Veloso, y Chico Buarque y Antônio Carlos Jobim que abren este artículo, el diálogo entre las dos artes puede ser directo, a manera de citación, o indirecto, por la incorporación de las conquistas técnicas de un arte en otro. Así es que el texto de Chico Buarque y Antônio Carlos Jobim, «Sabiá», dialoga, tomando como recurso una referencia casi directa como es la paráfrasis, con el famoso poema de Gonçalves Dias, "Canção do exílio», ${ }^{2}$ una poesía muy marcada por la musicalidad a partir del título mismo. Utilizando un procedimiento distinto - la autoreferencia y el metalenguaje-, el texto de Caetano Veloso, «Outro retrato», parte de una contradicción para llegar a una especie de autodefinición: una poesía hecha de música/una música hecha de poesía.

De ese modo, podemos decir que el fragmento elegido de «Sabiá» revela una preocupación por mantenerse dentro de la tradición lírica, con una predominancia

\footnotetext{
${ }^{2}$ El poema de Gonçalves Dias, «Canción del exilio», el más parafraseado y parodiado de la literatura brasileña, es el siguiente: «Mi tierra tiene palmeras/ En donde canta el sabiá;/ Las aves que aquí gorjean,/ No gorjean como allá.// En nuestro cielo hay más luces, / En nuestras vegas más flores, / En nuestros bosques más vida/ Y vida con más amores.// Al pensar, solo, en la noche/ Más placer encuentro allá;/ Mi tierra tiene palmeras/ En donde canta el sabiá.// Mi tierra tiene primores/ Como no los hallo acá;/ Al pensar — solo y de noche—/ Más placer encuentro allá;/ Mi tierra tiene palmeras/ En donde canta el sabiá.// No permita Dios que muera/ Sin que vuelva para allá;/ Sin que goce los primores/ Que no encuentro por aćá; Sin que vea las palmeras, / En donde canta el sabiás. El poema fue traducido por Wáshington Delgado y publicado en Tres poetas románticoss. Gonfalves Dias, Castro Alves, Sousândrade. Lima: Centro de Estudios Brasileños, 1984 (coleción Tierma Bmsileña, poesía).
} 
de la presentación del estado de ánimo del poeta, en este caso representado por la nostalgia. ${ }^{3}$ Tal texto, fuera de la propia temática y la forma utilizada, se distingue del fragmento de «Outro retrato», pues el referente del texto de Caetano ya no es el sentimiento del poeta, sino su modo de hacer y de pensar su arte poética. Según el compositor de Bahía, seguidor y amigo de los poetas concretos, su poesía proviene de un músico que no se interesa por la poesía (João Donato), y su música, de un poeta que no se interesa por la música (João Cabral de Melo Neto), lo que hace que concluyamos con que su poética, consciente de ser un género híbrido que reúne dos manifestaciones artísticas distintas, sigue la tendencia moderna de la antilira (la poesía final es antipoética y la música resultante es, por así decir, antimusical). Asimismo, el compositor percibe lo que existe de musical en la poesía, aunque esta se declare contraria a tal interferencia, y lo que existe de poético en la música, a pesar de que las palabras no sean utilizadas en la composición, como es el caso de João Donato.

\section{POETAS-MÚSICOS, POETAS Y MÚSICOS}

\section{L}

a conciencia demostrada en las dos composiciones presentadas de la música popular de Brasil en su relación con la poesía solo es posible porque los contactos entre las dos artes tienen una larga historia en la cultura brasileña, desde la época de la colonización del país. Una de las imágenes más conocidas del primer poeta importante de Brasil, el barroco Gregório de Matos Guerra, es justamente la del músico vagabundo que salía por las haciendas de Bahía cantando sus lundus, género musical popular que llegó al país junto con los negros africanos, y criticando a los gobernantes del lugar con su poesía satírica.

Otto momento importante para las relaciones entre poesía y música en Brasil es el Romanticismo, cuando los poetas, interesados en «cantan» las riquezas del país, buscaban representar las diferentes etnias ahí presentes, y hacían una poesía altamente musical donde el vocabulario y los ritmos indígenas y africanos eran reproducidos

\footnotetext{
${ }^{3} \mathrm{La}$ defnición tradicional de poesía lírica (un texto con fuerte presencia musical, ya que la lira era el instrumento utilizado por los poetas para acompañar la declamación de sus poemas) presenta una fuerte relación entre el poeta y la recordación de los sentimientos. Véase Starger, Emil. Concietos fundamentais de poética. Río de Janeiro: Tempo Brasileiro, 1975.

'Las tendencias líricas y antilíricas de la poesía moderna de Brasil fueron estudiadas por Luiz Costa Lima en Lira ef Antilira. Mário, Drummond, Cabral. Río de Janeiro: Civilização Brasileira, 1968.

${ }^{5}$ Un estudio importante sobre la evolución de la música erudita y popular en Brasil es el libro de Vasco MArrz. História de la Música en Brasil.Lima: Centro de Estudios Brasileños, 1985.
} 
en los poemas. ${ }^{6}$ En este sentido, dos poetas pueden ser destacados: Gonçalves Dias, en cuya poesía indigenista aparece, muchas veces, imitado el ritmo de los tambores y de las danzas de los indios, y Antonio de Castro Alves, cuya poesía grandilocuente y altisonante pretendía reproducir los horrores de la vida de los esclavos negros a fin de conmover a los oyentes.

Sin embargo, el momento cuando se da un intercambio aún más evidente entre los dos tipos de arte es el Modernismo brasileño, ya que los poetas, preocupados por estudiar los recursos musicales modernos para alterar el sentido y la forma del verso, al que pasaron a llamar «verso libre», hacían verdaderos ejercicios musicales que incorporaban a sus textos, en referencias directas e indirectas, tanto la música clásica como la popular; y los músicos, para ampliar sus investigaciones en el campo de los materiales musicales, procuraban estudiar los recursos utilizados por los poetas de entonces.

Esto ocurrió desde el comienzo del siglo XX y se intensificó a partir de la Semana de Arte Moderno, de 1922. Entre las actividades de la famosa «Semana» se encuentran las importantes participaciones de la pianista Guiomar Novaes, quien ejecutó piezas musicales de compositores modernos como Debussy, y del compositor Heitor Villa-Lobos, hasta hoy el más importante artista de música erudita de Brasil. Villa-Lobos, como hicieran Rimsky Korsakov en Rusia, Manuel de Falla en España y otros compositores en Europa, incorporó a sus composiciones los elementos nacionales, las canciones folclóricas, infantiles y populares, muchos de ellos conocidos después de las investigaciones etnográficas realizadas por escritores como Luís da Câmara Cascudo, Ascenso Ferreira y Mário de Andrade.

Asimismo, se puede afirmar que la poesía moderna de Brasil no existiría tal como se dio sin la participación de las conquistas en el campo de la música, pues toma prestado de esta uno de sus elementos más característicos, la disonancia, producida, sobre todo, por la incorporación del ruido. En el caso de la poesía, el ruido fue el resultado de la utilización de palabras tradicionalmente no poéticas, jergas, regionalismos, lenguaje infantil y marcas de oralidad, así como de la abolición de la sintaxis tradicional y

\footnotetext{
${ }^{6}$ Uno de los temas musicales clásicos más ejecutados en Brasil a principios del siglo XX es el épico $O$ guarani, del compositor Carlos Gomes, basado en la novela del mismo nombre del escritor romántico José de Alencar.

'Un interesante trabajo sobre la participación de la música en el Modernismo brasileño es libro de José Miguel WisNIx, O coro dos contrários: a música en torno da semana de 22. São Paulo: Duas Cidades/Secretaria de Estado da Cultura/Ciência e Tecnologia, 1977.
} 
de la inclusión de canciones populares reelaboradas a partir del uso de la parodia. Ejemplos de este procedimiento pueden ser observados en Oswald de Andrade, Mário de Andrade, Manuel Bandeira y Murilo Mendes, los tres últimos, además de poetas, fueron investigadores y críticos musicales. Mário de Andrade fue, además de etnógrafo y compositor de canciones populares, profesor de piano en el Conservatorio Musical de São Paulo; Manuel Bandeira fue crítico de música y tenía entre sus grandes amigos a los músicos bohemios de Río de Janeiro, que, incluso, musicalizaron algunos de sus poemas; Murilo Mendes, cuya disonancia en la poesía fue apuntada diversas veces por los críticos literarios, ${ }^{8}$ estaba muy interesado en las conquistas musicales de compositores como Stravinsky y Schoenberg y atento a la presencia del jazz en la música brasileña, elementos que están referidos directa e indirectamente en su poética.

En las décadas de 1940, 1950 y 1960, los poetas Cecília Meireles y Vinícius de Moraes, siguiendo una línea de trabajo más aproximada a la tradición lírica, mantuvieron el diálogo entre poesía y música en su producción literaria. Varios de los libros de Cecilia Meireles tratan de los temas musicales y muchos de sus poemas poseen títulos oriundos de este campo, especialmente sus nocturnos y canciones. En el caso de Vinícius de Moraes es aún más flagrante la relación entre las dos artes: el poeta —o «poetinha», como es llamado— fue uno de los compositores populares más celebrados de Brasil hasta los años 1980, sus temas musicales (sambas, baladas románticas, bossa nova) fueron grabados por un grupo muy amplio de cantantes y siempre presentaban un estrecho vínculo con sus textos poéticos y su temática dividida entre las relaciones amorosas y las críticas sociales.

A fines de los años 1960, con la presencia de movimientos culturales más politizados y críticos en relación con la dictadura militar de Brasil, y la mitad de la década de 1980, con la retomada democrática y la inclusión del país en la sociedad posmoderna, dos corrientes de la música y su correspondiente poesía pueden ser destacadas en el escenario cultural de Brasil. Una de ellas es la música de protesta, que tiene como sus representantes más respetados a los compositores Geraldo Vandré, Edu Lobo, el mismo Vinícius de Moraes y Chico Buarque de Holanda, las canciones de este último ya fueron comparadas con la poesía de Carlos Drummond de

"Este aspecto es estudiado, entre otros, por Haroldo de CAMPos en su ensayo «Murilo Mendes y el mundo substantivon. En Brasil transamericano. Traducción y prólogo de Amalia Sato. Buenos Aires: El Cuenco de Plata, 2004. 
Andrade. La otra es el tropicalismo de Caetano Veloso y Gilberto Gil, un movimiento cultural amplio que buscaba rescatar las conquistas teóricas y prácticas de la vanguardia modernista, sobre todo con la revaloración de los textos antropofágicos de Oswald de Andrade y el uso de la parodia y de la intertextualidad, y que tenía como su correspondiente en la literatura la poesía concreta de los hermanos Haroldo y Augusto de Campos, en especial con referencia a la música el segundo de ellos.

Un tema musical siempre visto como resultado de este encuentro entre las dos artes en el tropicalismo es «Batmacumba», grabada por Gilberto Gil, en 1968, en el disco Tropicalia opanis et circenses:

batmacumbaiéié batmacumbaoba
batmacumbaiéié batmacumbao
batmacumbaiéié batmacumba
batmacumbaiéié batmacum
batmacumbaiéié batman
batmacumbaiéié bat
batmacumbaiéié ba
batmacumbaiéié
batmacumbaié
batmacumba
batmacum
batman
bat
ba
bat
batman
batmacum
batmacumba
batmacumbaié
batmacumbaiéié
batmacumbaiéié ba
batmacumbaiéié bat
batmacumbaiéié batman
batmacumbaiéié batmacum
batmacumbaiéié batmacumbao
batmacumbaiéié batmacumbaoba


En Música popular e moderna poesia brasileira, Affonso Romano de Sant'Anna llama la atención con respecto al aspecto visual de esta composición, en especial la construcción de la imagen del murciélago, obtenida con la disposición gráfica del texto, posible en términos estéticos por la referencia a Batman, el héroe de la serie televisiva, muy popular en el Brasil de entonces. ${ }^{9}$ En el texto también se puede observar el trabajo de destrucción de la sintaxis tradicional, la incorporación de palabras extranjeras (batman), la mezcla de culturas (africana/americana) y, en el campo sonoro, el juego con la repetición de los mismos elementos, con predominancia de la percusión. La operación mental necesaria para la comprensión y la apreciación de este tipo de música la aproxima, una vez más, a la corriente antilírica de la poesía moderna brasileña que apuntábamos al comienzo de este artículo.

Después de los años 1980, con la vuelta de la democracia, la invasión de los grupos de rock (internacionales y nacionales), el boom de la música sertaneja en las radios y canales de televisión en Brasil y el desarrollo del cine como opción de entretenimiento, las relaciones entre las dos artes tuvieron una disminución. Compositores como Caetano Veloso y Chico Buarque, siempre estudiados como promotores de la aproximación de la música a la literatura, dejaron de ser el puente entre las dos actividades: el primero se dedica hoy más a la composición y organización de música para el cine o a la interpretación de los clásicos (o estándares); el segundo, de cierta forma, abandonóla música y se dedicó, con merecido éxito, a la escritura de novelas.

De ese modo, tanto la poesía como la música popular en Brasil hoy en día están pasando por una redefinición y es muy difícil determinar tendencias y novedades, debido, sobre todo, a la gran variedad de estilos y de temas utilizados en las composiciones, sean poéticas o musicales. Sin embargo, para retomar las líneas de la música y la poesía brasileñas, dos nombres, por lo menos, pueden ser destacados en este escenario: el ex miembro del grupo de rock Os Titãs y actual integrante de los Tribalistas, Arnaldo Antunes, y el poeta y compositor Antonio Cícero. Arnaldo Antunes, estudioso de la literatura y poeta, ya realizó composiciones para grupos de danzas y publicó libros de poemas; influenciado por los concretistas y con un tipo de composición muy marcado por la intertextualidad y la parodia, el músico paulista puede ser identificado como un continuador de la tradición antilírica de la

\footnotetext{
'Véase Sant'Anna, Affonso Romano de. Música popular e moderna poesia brasileira. Petrópolis: Vozes, 1980, pp. 260-261.
} 
poesía brasileña. Por su parte, Antonio Cícero, sin ser excesivamente melodioso, propone una poesía donde el trabajo con el lenguaje se percibe como esencialmente lírico y dependiente de la música." 


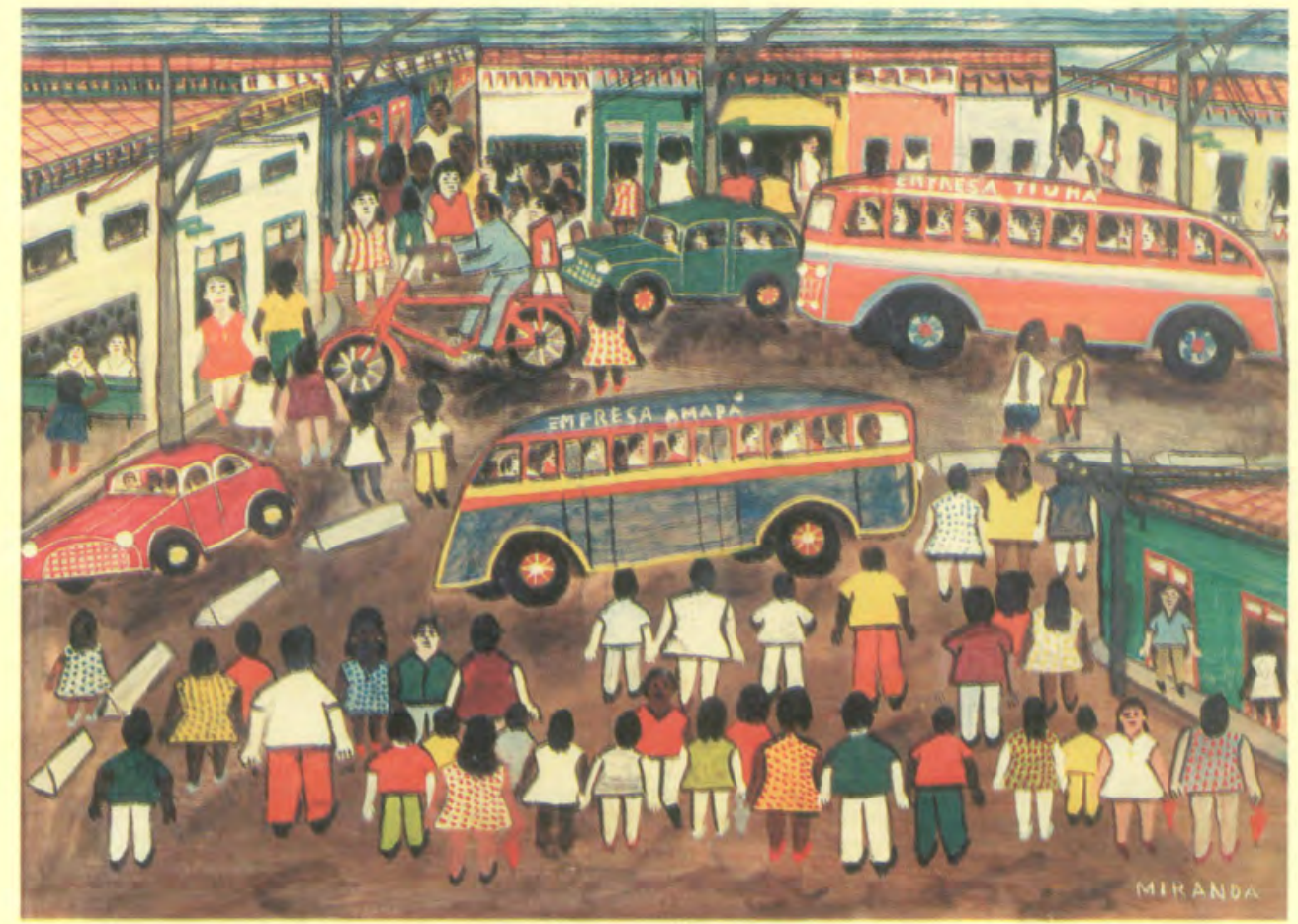

O tráfego (1974)

MirandA 